\title{
Quality Flag of GOSAT/FTS Products Taking into Account Estimation Reliability
}

\author{
Kohei Arai ${ }^{1}$, Takashi Higuchi ${ }^{2}$, \\ Hiroshi Okumura $^{3}$ \\ Department of Information Science \\ Saga University, Saga City, Japan
}

\author{
Hirofumi Ohyama ${ }^{4}$ \\ NIES: National Institute of \\ Environmental Studies, Tsukuba Japan
}

\author{
Shuji Kawakami ${ }^{5}$, Kei Shiomi ${ }^{6}$ \\ JAXA: Japan Aeronautics Exploration \\ Agency, Tsukuba, Japan
}

\begin{abstract}
Quality and cloud flags of GOSAT/FTS: Fourier Transform Spectrometer onboard Greenhouse gasses Observation Satellite products taking into account cirrus clouds and thick aerosols are considered and proposed. Influence due to cirrus and thick aerosol on estimation of column $\mathrm{CO}_{2}$ and $\mathrm{CH}_{4}$ with GOSAT/FTS data is clarified. Relatively large estimation errors are observed in column $\mathrm{CO}_{2}$ and $\mathrm{CH}_{4}$ retrievals with FTS data in some atmospheric conditions. In order to find such cases, retrieval results and quality/cloud flags in the GOSAT/FTS data products are checked. Through the investigation, it is found that relatively large error is caused by convergence problem due to cirrus clouds and thick aerosols. In the proposed paper, some of the cases of which relatively large estimation error is occurred at the Saga TCCON (The Total Carbon Column Observing Network) site are investigated. Also, a comparative study is conducted between standard products provided by NASA/JPL and the Levenberg-Marquardt based least square method of column $\mathrm{CO}_{2}$ and $\mathrm{CH}_{4}$ retrieval. It is suggested that some improvements of estimation accuracy of column $\mathrm{CO}_{2}$ and $\mathrm{CH}_{4}$ retrieval with GOSAT/FTS data can be expected.
\end{abstract}

Keywords-Levenberg-Marquardt; FTS; GOSAT; aerosol; cirrus cloud

\section{INTRODUCTION}

GOSAT: Greenhouse gases Observing Satellite is a greenhouse gas observation technology satellite ("IBUKI" in Japanese) 1 jointly developed by the Ministry of the Environment, the National Institute for Environmental Studies (NIES), and the Japan Aerospace Exploration Agency (JAXA). Observe the concentration distribution of greenhouse gases such as carbon dioxide and methane gas, which are considered to be the cause of global warming, from outer space. On January 23, 2009, it was launched from the Tanegashima Space Center at H-IIA Launch Vehicle No. 15. Starting acquiring observation data from February 2009, in May 2009 uncalibrated value analysis results on a global scale have been published.

GOSAT carries TANSO - FTS (TANSO: Thermal And Near Infrared Sensor for Carbon Observation, FTS: Fourier Transform Spectrometer) ${ }^{2}$ is a main IBUKI sensor measuring carbon dioxide and methane gas. We observe spectra of solar light (near infrared rays) reflected by the earth surface and

\footnotetext{
${ }^{1}$ http://www.gosat.nies.go.jp/

${ }^{2}$ http://www.eorc.jaxa.jp/GOSAT/instrument_1.html
}

spectra of the light radiated from the earth's atmosphere and the ground surface (far infrared rays) by Fourier spectroscopy ${ }^{3}$.

Since carbon dioxide and methane present in the atmosphere have the property of absorbing light of a specific wavelength, the amount of carbon dioxide and methane that existed in the path of light, depending on the degree of absorption of light transmitted through the atmosphere, It can be calculated. Absorption band of carbon dioxide around 1.6 $\mu \mathrm{m}$ and around $2.0 \mu \mathrm{m}$ is important as a wavelength band containing much information near the ground surface. On the other hand, the absorption band around $14 \mu \mathrm{m}$ is mainly used to obtain altitude information higher than $2 \mathrm{~km}$. The accumulated amount of carbon dioxide gas is measured by short wavelength infrared band 1 to 3 (SWIR: Short Wave Infrared Band 1-3), and the vertical concentration distribution of carbon dioxide is measured by thermal infrared band 4 (TIR: Thermal Infrared Band 4). For conditions without error factors such as clouds and aerosols, we aim to measure errors within $1 \%$.

GOSAT also carries TANSO-CAI (CAI: Cloud and Aerosol Imager $)^{4}$ is an image sensor used for determination of the presence or absence of clouds and measurement of aerosol (atmospheric particulate matter), which is an error factor when measuring carbon dioxide at TANSO-FTS. It is a secondary sensor of IBUKI. It is used for correction of measured data obtained by TANSO-FTS.

CAI observes the state of the atmosphere and the surface of the earth as an image in the daytime. The presence or absence of clouds in a wide range including the field of view of FTS is judged from the observation data, and in the case of aerosol or thin clouds, the characteristics of the cloud and the amount of aerosol are calculated. These information are used to correct the influence of clouds and aerosols contained in the spectrum obtained from FTS.

Development of transportable Lidar $^{5}$ for validation of GOSAT satellite data products is well reported [1]. Also, advanced validation of the GOSAT observed $\mathrm{CO}_{2}$ and $\mathrm{CH}_{4}$ at TCCON (The Total Carbon Column Observing Network) ${ }^{6}$ and prioritized observation sites is reported [2]. Meanwhile, Observations of $\mathrm{XCO}_{2}$ and $\mathrm{XCH}_{4}$ (total column $\mathrm{CO}_{2}$ and $\mathrm{CH}_{4}$

\footnotetext{
${ }^{3}$ https://en.wikipedia.org/wiki/Fourier-transform_spectroscopy

${ }^{4}$ http://www.eorc.jaxa.jp/GOSAT/instrument_2_j.html

${ }^{5} \mathrm{https}: / /$ ja.wikipedia.org/wiki/LIDAR

${ }^{6}$ https://tccon-wiki.caltech.edu/
} 
$\mathrm{CO}_{2}$ and $\mathrm{CH}_{4}$ ) with ground-based high-resolution FTS at Saga, Japan and comparisons with GOSAT products is discussed [3]. On the other hand, evaluation of cirrus cloud detection accuracy of GOSAT/CAI and Landsat- $8 \mathrm{OLI}^{7}$ with laser radar: lidar and confirmation with CALIPSO/CALIOP ${ }^{8}$ data is conducted [4] together with a comparative study on cloud parameter estimation among GOSAT/CAI, MODIS ${ }^{9}$, CALIPSO/CALIOP and Landsat-8/OLI with laser radar as truth data [5].

Advanced validation of the GOSAT observed $\mathrm{CO}_{2}$ and $\mathrm{CH}_{4}$ at priotized observation sites is reported [6]. On the other hand, Web based data acquisition and management system for GOSAT validation Lidar data analysis is developed [7]. Meanwhile, observation of aerosol parameters at Saga using GOSAT product validation Lidar is discussed [8]. Meantime, improvement of web-based data acquisition and management system for GOSAT validation Lidar data analysis (2013) is also discussed [9] together with observation of aerosol properties at Saga using GOSAT product validation LiDAR [10].

Impact of aerosol and cirrus clouds on the GOSAT observed $\mathrm{CO}_{2}$ and $\mathrm{CH}_{4}$ inferred from ground based lidar, skyradiometer ${ }^{10}$ and FTS data at prioritized observation sites,(2013) is clarified [11]. Comparison of lower tropospheric ozone column observed by DIAL: Differential Absorption Lidar $^{11}$ and GOSAT TANSO-FTS TIR is made [12]. Furthermore, impact of aerosols and cirrus on the GOSAT onboard $\mathrm{CO}_{2}$ and $\mathrm{CH}_{4}$ inferred from ground based Lidar, skyradiometer and FTS data at prioritized observation sites is discussed [13]. Then, on the validation results of five year GOSAT SWIR XCO $\mathrm{XCO}_{2}$ and $\mathrm{XCH}_{4}$ (total column $\mathrm{CO}_{2}$ and $\mathrm{CH}_{4}$ ) data is well reported [14].

Lidar observations at priotized sites for GOSAT validation is reported [15] together with lidar observation at TCCON site to investigate the influence of particles for GOSAT data [16]. On the other hand, influence due to cirrus and thick aerosol on estimation of column $\mathrm{CO}_{2}$ and $\mathrm{CH}_{4}$ with GOSAT/FTS data is discussed [17].

From the methodological point of view, estimation of $\mathrm{XCO}_{2}$ and $\mathrm{XCH}_{4}$ can be done with FTS data based on least square method. FTS data, however, is affected by clouds and thick aerosols. In order to avoid the cloud influence, clouds are detected with CAI imagery data then the FTS data which suffered from the clouds are identified with cloud flag. It, however, does not work properly. Thin cirrus type of clouds cannot be detected with CAI instrument. Other than this, quality flag can be used for analysis of the FTS data in concern. FTS data seems to also be suffered from thick aerosols. Such these FTS data are not reliable enough for analysis. Therefore, it is desirable to reconsider the method for reliability flag rather than the present quality flag.

\footnotetext{
${ }^{7}$ https://en.wikipedia.org/wiki/Landsat_8

${ }^{8}$ https://www-calipso.larc.nasa.gov/

${ }^{9}$ https://modis.gsfc.nasa.gov/

${ }^{10} \mathrm{http}: / / \mathrm{www}$. kippzonen.com/ProductGroup/31/Sky-radiometers

${ }^{11}$ https://www.esrl.noaa.gov/csd/groups/csd3/instruments/lidar/dial.html
}

Past FTS data are checked from the point of view of reliability. By using TCCON site of calibration site data, it is possible to check the estimation accuracy (discrepancy between the true and the estimated $\mathrm{XCO}_{2}$ and $\mathrm{XCH}_{4}$ ). Through careful check of the reliability, it is found that there is relation between reliability and clouds and thick aerosol. This paper intends to discuss this matter and suggest some reliability flag to the FTS data in concern.

Due to the fact that GOSAT/FTS does not cover the wavelength of water vapor absorption, it is hard to estimate influence of water vapor and clouds on estimation of $\mathrm{XCO}_{2}$ and $\mathrm{XCH}_{4}$. Therefore, it is required to use other sensor data than the GOSAT/FTS data for estimation of water vapor, aerosol, and clouds influences..

The following section describes current status of the GOSAT/FTS derived $\mathrm{XCO}_{2}$ and $\mathrm{XCH}_{4}$ followed by the relation between discrepancy between the true and the estimated $\mathrm{XCO}_{2}$ and $\mathrm{XCH}_{4}$ as well as clouds and thick aerosols measured with sky-radiometer. Then, some methods which allows to detect clouds and thick aerosols by using other data sources derived from the other mission instruments such as MODIS. After that, conclusion is described together with some discussions and with future research works.

\section{RESEARCH BACKGROUND}

\section{A. Present Status of GOSAT Project}

GOSAT satellite is operated in good health condition. In order to calibrate GOSAT TANSO-FTS, TCCON sites are also operated. One of the TCCON sites is situated at Saga University in Saga, Japan. Saga ground based-FTS operation started from July 2011. GOSAT targets at Saga are acquired every 3 days. In conjunction of GOSAT operation at Saga, OCO-2: Orbiting Carbone Observatory- $2^{12}$ can target 2 days in 16-day revisit cycle of GOSAT satellite. Fig. 1 shows outlook of the Saga TCCON site.

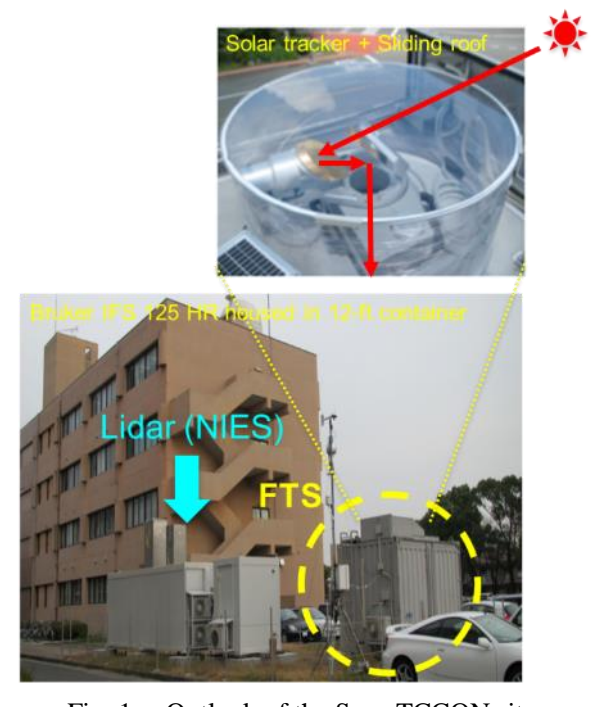

Fig. 1. Outlook of the Saga TCCON site.

\footnotetext{
${ }^{12}$ https://oco.jpl.nasa.gov/
} 
From the roof of the FTS container situated at Saga University, Saga Japan, solar irradiance comes in the ground based FTS instrument. The FTS measures solar irradiance which is absorbed by atmospheric molecules, aerosol, water vapor. Based on Fourier spectrum analysis, $\mathrm{XCO}_{2}$ and $\mathrm{XCH}_{4}$ can be estimated. On the other hand, sky-radiometer and skyview camera are situated at the top roof of the building at Saga University nearby FTS container. From the sky-radiometer, aerosol refractive index and size distribution can be estimated while existing visible clouds can be observed with sky-view camera.

Fig. 2 shows an example of GOSAT observation pattern around Japanese vicinity. Along with the GOSAT satellite track, grid observation can be done while target areas can also be observed in GOSAT operation. Fig. 2 also shows the location of Saga TCCON site. From the 2011 to up to now, not only $\mathrm{XCO}_{2}$ and $\mathrm{XCH}_{4}$ but also $\mathrm{XCO}, \mathrm{XN}_{2} \mathrm{O}$ can be estimated.

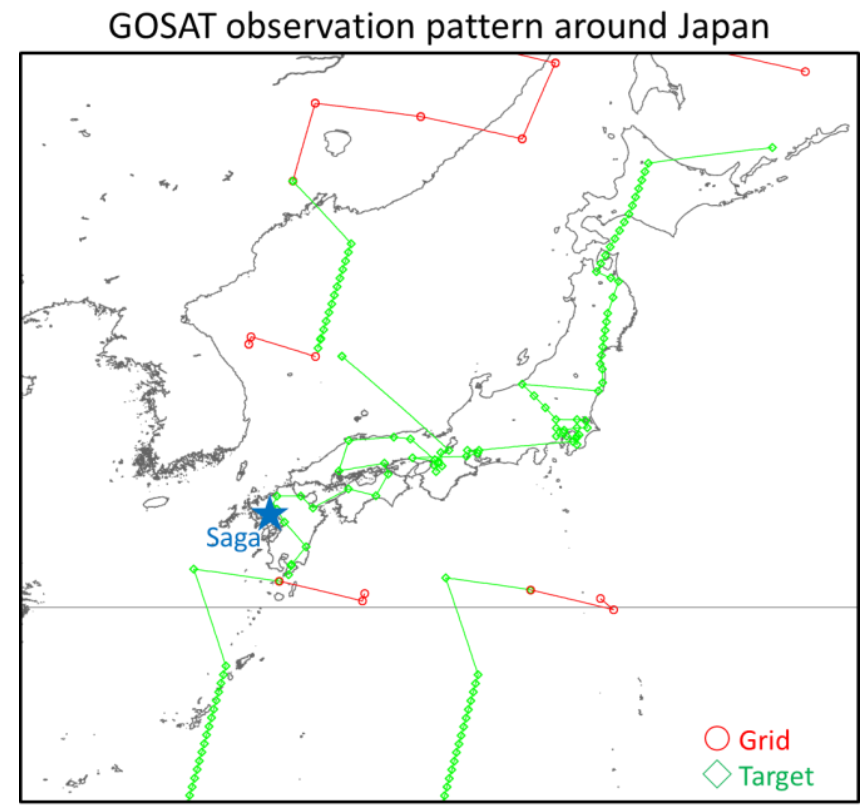

Fig. 2. Example of GOSAT observation pattern around Japanese vicinity.
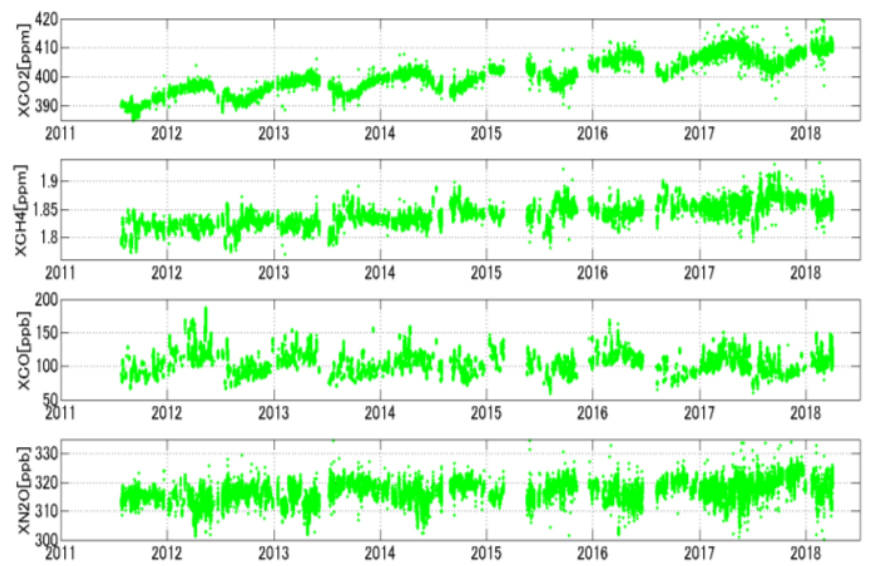

Fig. 3. Trends of the $\mathrm{XCO}_{2}$ (upper), $\mathrm{XCH}_{4}$ (second), $\mathrm{XCO}$ (third), $\mathrm{XN}_{2} \mathrm{O}$ (bottom)
Fig. 3 shows the trends of the $\mathrm{XCO}_{2}$ (in unit of ppm), $\mathrm{XCH}_{4}$ (in unit of ppm), $\mathrm{XCO}$ (in unit of ppb), $\mathrm{XN}_{2} \mathrm{O}$ (in unit of $\mathrm{ppb}$ ) which are estimated with GOSAT FTS data. On the other hand, Fig. 4 shows $\mathrm{XCO}_{2}$ and $\mathrm{XCH}_{4}$ estimated from the $\mathrm{mIES}$ GOSAT V02.72 observation and from the ground based FTS observation at - Saga-TCCON site. Overall trends of $\mathrm{XCO}_{2}$ and $\mathrm{XCH}_{4}$ estimated with GOSAT-FTS data and the ground based FTS show almost same.
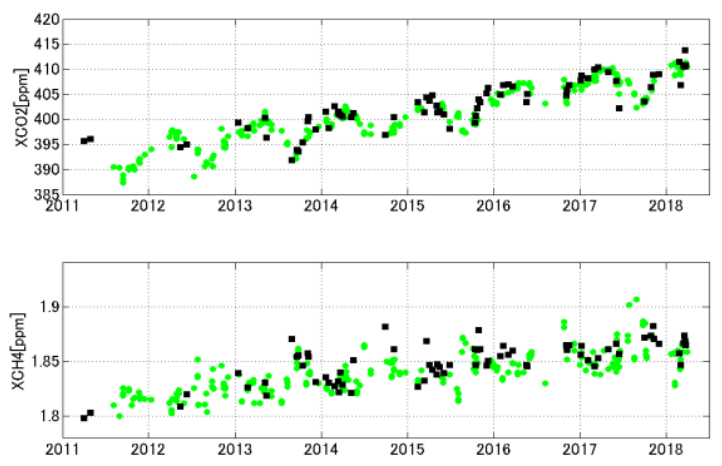

Fig. 4. $\mathrm{XCO}_{2}$ and $\mathrm{XCH}_{4}$ estimated from the NIES GOSAT V02.72 observation and from the ground based FTS observation at $\bullet$ Saga-TCCON site

There are five major datasets, ACOS/GOSAT, AIRS/AQUA, OCO-2/OCO-2, TES/AURA, TCCON (ground based FTS $)^{13}$.

Correlation plots of NIES GOSAT v02 $\mathrm{XCO}_{2}$ and $\mathrm{XCH}_{4}$ and ground based FTS data derived $\mathrm{XCO}_{2}$ and $\mathrm{XCH}_{4}$ are shown in Fig. 5. The ground based FTS within $\pm 30 \mathrm{~min}$. of GOSAT overpass time are averages. Solid and dashed lines denote linear fit with an intercept of 0 and 1-to-1 line respectively.

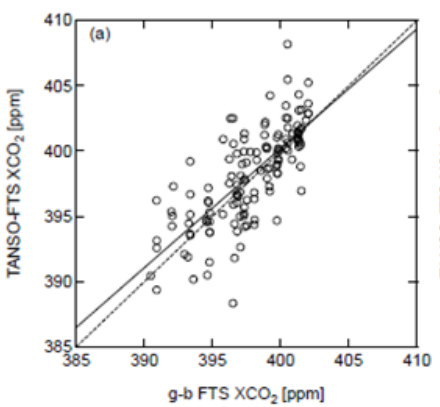

(a) $\mathrm{XCO}_{2}$

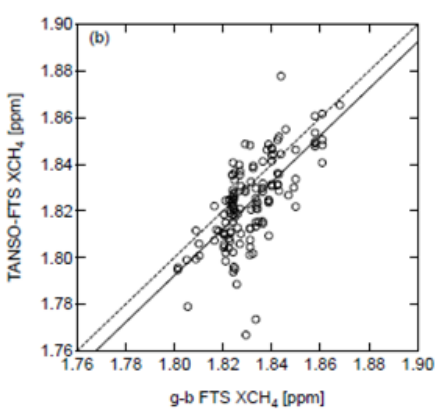

(b) $\mathrm{XCH}_{4}$
Fig. 5. Correlation plots of NIES GOSAT v02 $\mathrm{XCO}_{2}$ and $\mathrm{XCH}_{4}$

Average differences as (TANSO-FTS minus ground-based FTS) are as follows,

$$
\begin{aligned}
& \mathrm{XCO}_{2}: 0.40+/-2.51 \mathrm{ppm} \\
& \mathrm{XCH}_{4}:-7.6+/-13.7 \mathrm{ppb}
\end{aligned}
$$

As shown in Fig. 4 and 5, there are some significant discrepancy between GOSAT/FTS derived and the ground based FTS derived $\mathrm{XCO}_{2}$ and $\mathrm{XCH}_{4}$. In particular, relatively

\footnotetext{
${ }^{13}$ https://co2.jpl.nasa.gov/\#mission=ACOS
} 
large difference between both is observed at the specific days. Therefore, careful check at the specific dates of estimated $\mathrm{XCO}_{2}$ and $\mathrm{XCH}_{4}$ has to be done.

\section{B. Check the GOSAT Products, Flags}

Flag information is stored in the analyzed data. There is a high possibility that the estimation does not go well if the flag $\neq 0$. For instance, Fig. 6 shows an example of a relation between sky-view camera images and Saga-TCCON flag. As shown in Fig. 6, flag=0 for the clear sky condition (a) while flag=33 for the partly cloudy condition (b).

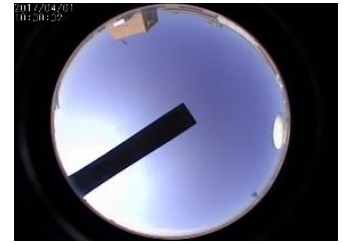

(a)js20170401saee0a.0020

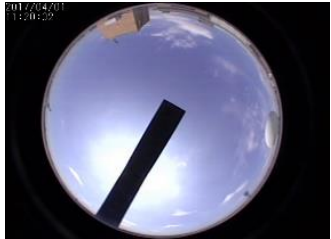

(b) js20170401saee0a.0062

Flag=33
Fig. 6. Example of a relation between sky-view camera images and SagaTCCON flag.

Fig. 7 shows a result from the comparison between the changes of solar irradiation data (red) and Saga-TCCON flag (blue).

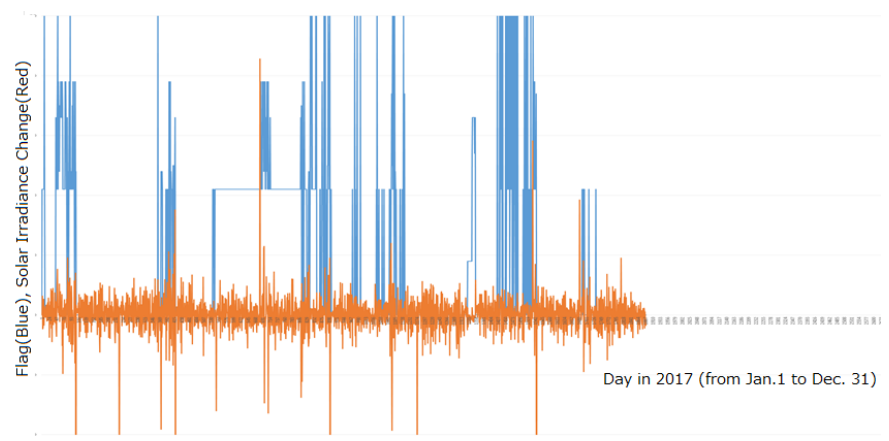

Fig. 7. Result from the comparison between the changes of solar irradiation data (red) and Saga-TCCON flag (blue).

Coincidentally, the flag is large when the solar irradiation changes a lot. When the weather condition is changed from clear sky to cloudy, solar irradiation is also changed a lot. Therefore, both are occurred coincidentally. Table 1 shows the relation between Saga-TCCON flag and Mean and Standard deviation of solar irradiation as well as correlation coefficient between Saga-TCCON flag and solar irradiation.

TABLE I. RELATION BETWEEN SAGA-TCCON FlAG AND MEAN AND STANDARD DEVIATION OF SOLAR IRRADIATION AS WELL AS CORRELATION COEFFICIENT BETWEEN SAGA-TCCON FLAG AND SOLAR IRRADIATION.

\begin{tabular}{|l|l|l|}
\hline Saga-TCCON flag & Off & On \\
\hline Mean of daily changes of solar irradiation & 1.979 & 2.472 \\
\hline Standard deviation & 3.340 & 4.218 \\
\hline Correlation & 0.481 & 0.580 \\
\hline
\end{tabular}

Saga-TCCON flag is on when the solar irradiation is relatively large. Therefore, there is a possibility to find estimated $\mathrm{XCO}_{2}$ and $\mathrm{XCH}_{4}$. with relatively poor accuracy by taking into account the changes in solar irradiation.

\section{Comparison of Estimated $\mathrm{XCO}_{2}$ and $\mathrm{XCH}_{4}$ by the}

Proposed Least Square Method based on the Levenberg-

\section{Marquardt with the Conventional Method}

Typical cases of estimation accuracy is relatively good (fine weather: clear sky condition) and of estimation error seems to be large comparatively (cloudy condition) are selected. Those are FTS data of April 4, 12, 13, 19, and 24 2018. Fig. 8 shows sky-view camera images (Top left: April 4, Top right: April 12, Middle left: April 13, Middle right: April 19 and Bottom: April 24). The left side image shows cloud condition in the morning while the right side image shows cloud condition in the afternoon. It is clear that it is clear in the morning on April 4, 13 and 24 while there are some clouds in the afternoon on April 4, 12, 24. In accordance with the Saga brunch of the JMA: Japan Meteorological Agency, CC: Cloud Coverage at 12:00 and 15:00 of each day is as follows,

April 4: 2, 7. April 12: 2, 3. April 13: 0, 7. April 19: 3, 7. April 24: 0, 8.

It, however, is not always true. There are some visible cirrus clouds in the morning on April 12 clearly. Therefore, FTS data derived $\mathrm{XCO}_{2}$ and $\mathrm{XCH}_{4}$ on April 12 is compared to that of April 13.

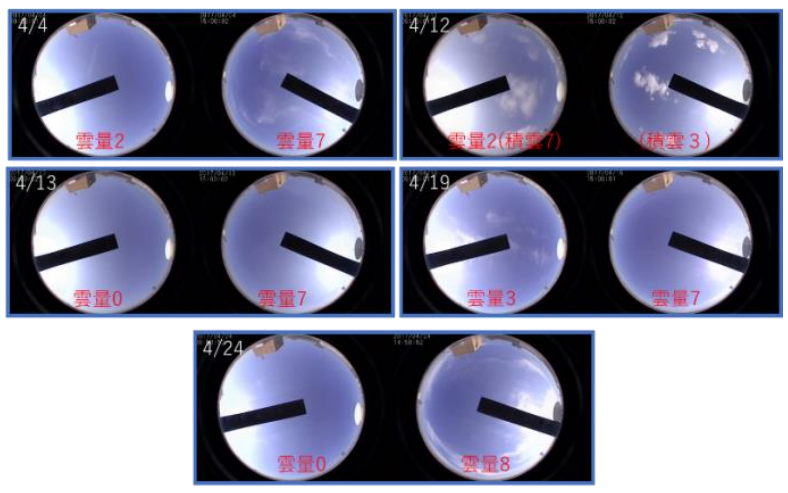

Fig. 8. Sky-view camera images (Top left: April 4, Top right: April 12 Middle left: April 13, Middle right: April 19 and Bottom: April 24)

As mentioned in the previous section, the conventional method for estimation of $\mathrm{XCO}_{2}$ and $\mathrm{XCH}_{4}$ is called GGG algorithm. Table 2 shows a comparison of mean and standard deviation of the estimated $\mathrm{XCO}_{2}$ between GGG and the proposed least square method based on the LevenbergMarquardt of nonlinear least square method. As shown in Table 2, relatively large discrepancy between the estimated $\mathrm{XCO}_{2}$ is observed during 9 a.m. and 11:30 a.m. on April 12. Those estimated $\mathrm{XCO}_{2}$ is shown in Fig. 9. In the figure, black dots denote $\mathrm{XCO}_{2}$ of GGG while blue dots denote $\mathrm{XCO}_{2}$ of the proposed least square method.

These discrepancy is caused by the difference between algorithms of the proposed least square and GGG. Therefore, there is a possibility to check the reliability of estimated $\mathrm{XCO}_{2}$ by using the discrepancy between both. 
TABLE II. COMPARISON OF MEAN AND STANDARD DEVIATION OF THE EsTIMATED $\mathrm{XCO}_{2}$ BETWEEN GGG AND THE PROPOSED LEAST SQUARE METHOD

\begin{tabular}{|l|c|r|r|r|r|}
\hline & \multicolumn{1}{|l|}{ April 4 } & \multicolumn{1}{|l|}{ April 12 } & \multicolumn{1}{|l|}{ April 13 } & \multicolumn{1}{|l}{ April 19 } & April 24 \\
\hline Mean (Proposed) & 415.98 & 373.64 & 415.23 & 413.6 & 413.33 \\
\hline St.Dev.(Proposed) & 0.81 & 37.58 & 0.93 & 0.59 & 1.11 \\
\hline Mean (GGG) & 409.45 & 404.21 & 410.69 & 408.66 & 410.47 \\
\hline St.Dev.(GGG) & 0.52 & 5.92 & 1.16 & 1.18 & 1.05 \\
\hline
\end{tabular}

$4 / 12$

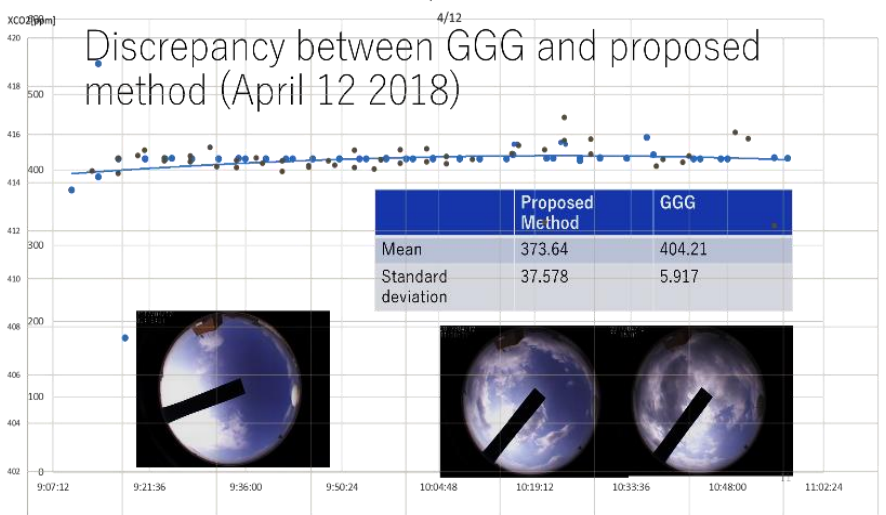

Fig. 9. Estimated $\mathrm{XCO}_{2}$ derived from $\mathrm{GGG}$ and from the proposed least square method (Black dots denote $\mathrm{XCO}_{2}$ of GGG while Blue dots denote $\mathrm{XCO}_{2}$ of the proposed least square method.

\section{Possible Causes of Relatively Large $\mathrm{XCO}_{2}$ Estimation Error}

Cloud condition on April 122018 is shown in Fig. 10. Cloud Coverage ratio (CC) at 9:00 is 7 (Cumulus clouds), then $\mathrm{CC}$ at $12: 00$ is 2 (Cirrus clouds), and $\mathrm{CC}$ at 15:00 is 3 (Cumulus clouds), respectively. Also, hourly Solar Irradiance (SI) at 9:00 is 1.22 , then SI at 12:00 is 1.96 , and SI at 15:00 is 2.72. Averaged CC of the day is 6 and total solar irradiance a day is $20.88 \mathrm{MJ} / \mathrm{m}^{2}$.

Other than these, solar direct and diffuse irradiance are measured with sky-radiometer, POM-1 of sun-photometer and aureole-meter which is manufactured by Prede Co. Ltd. in Japan. Using this data, aerosol refractive index, size distribution, single scattering albedo, atmospheric optical depth, etc. can be estimated.

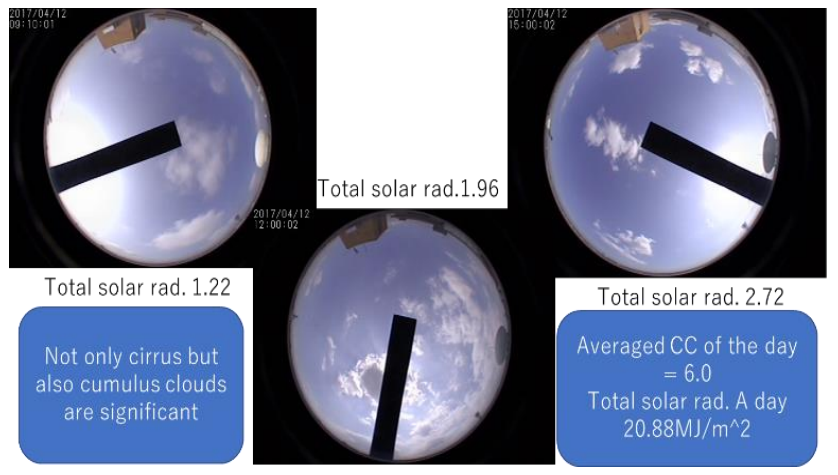

Fig. 10. Cloud condition on April 122018
TABLE III. SINGLE SCATTERING AlBEDO AND TOTAL ATMOSPHERIC OPTICAL DEPTH

(A)SINGLE SCATTERING ALBEDO

\begin{tabular}{|c|c|c|c|c|c|}
\hline Wavelength $[\mu \mathrm{m}]$ & \multicolumn{1}{c|}{$\begin{array}{c}\text { April } \\
\mathbf{4}\end{array}$} & \multicolumn{1}{c|}{$\begin{array}{c}\text { April } \\
\mathbf{1 2}\end{array}$} & \multicolumn{1}{c|}{$\begin{array}{c}\text { April } \\
\mathbf{1 3}\end{array}$} & \multicolumn{1}{c|}{$\begin{array}{c}\text { April } \\
\mathbf{1 9}\end{array}$} & \multicolumn{1}{c|}{$\begin{array}{c}\text { April } \\
\mathbf{2 4}\end{array}$} \\
\hline 0.38 & 0.841 & 0.826 & 0.846 & 0.787 & 0.808 \\
\hline 0.4 & 0.961 & 0.927 & 0.960 & 0.908 & 0.954 \\
\hline 0.5 & 0.965 & 0.948 & 0.989 & 0.938 & 0.953 \\
\hline 0.675 & 0.962 & 0.948 & 0.990 & 0.932 & 0.952 \\
\hline 0.87 & 0.750 & 0.854 & 0.813 & 0.897 & 0.717 \\
\hline
\end{tabular}

(b)Total Atmospheric Optical Depth

\begin{tabular}{|c|c|c|c|c|c|}
\hline Wavelength $[\mu \mathrm{m}]$ & April4 & $\begin{array}{l}\text { April } \\
12\end{array}$ & $\begin{array}{l}\text { April } \\
13\end{array}$ & $\begin{array}{l}\text { April } \\
19\end{array}$ & $\begin{array}{l}\text { April } \\
24\end{array}$ \\
\hline 0.38 & 0.303 & 0.681 & 0.503 & 0.257 & 0.263 \\
\hline 0.4 & 0.271 & 0.622 & 0.456 & 0.238 & 0.226 \\
\hline 0.5 & 0.201 & 0.501 & 0.344 & 0.201 & 0.165 \\
\hline 0.675 & 0.123 & 0.369 & 0.217 & 0.159 & 0.102 \\
\hline 0.87 & $5 \quad 0.099$ & 0.312 & 0.171 & 0.145 & 0.0878 \\
\hline
\end{tabular}

Single scattering albedo of each day is shown in Table 3 (a) while total atmospheric optical depth of each day is shown in Table 3 (b), respectively.

The single scattering albedo on April 12 is relatively small while the total atmospheric optical depth on April 12 is comparatively large. Therefore, absorption in the atmosphere is relatively large while comparatively thick atmosphere on April 12.

Imaginary part of aerosol refractive index estimated for 9:00 to 10:20 a.m. on April 12 is shown in Fig. 11 (a) while that of 9:50 to 15:00 on April 13 is shown in Fig. 11 (b), respectively. Not so significant difference is observed between both of imaginary part of aerosol refractive index estimated for April 12 and April 13. Also, relatively large changes are observed for imaginary part of aerosol refractive index during from 9:00 to 10:20 on April 12 while that for 9:50 to 15:00 on April 13 is very stable.

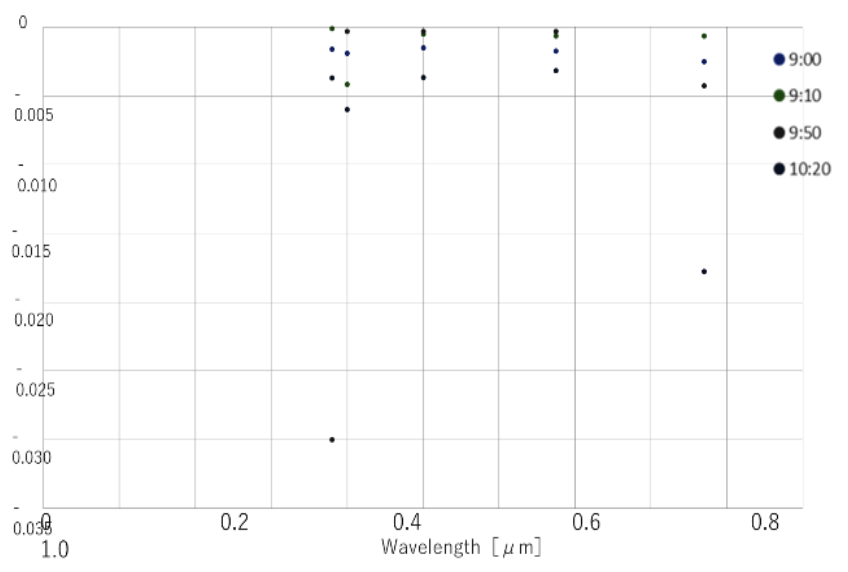

(a)April 12 


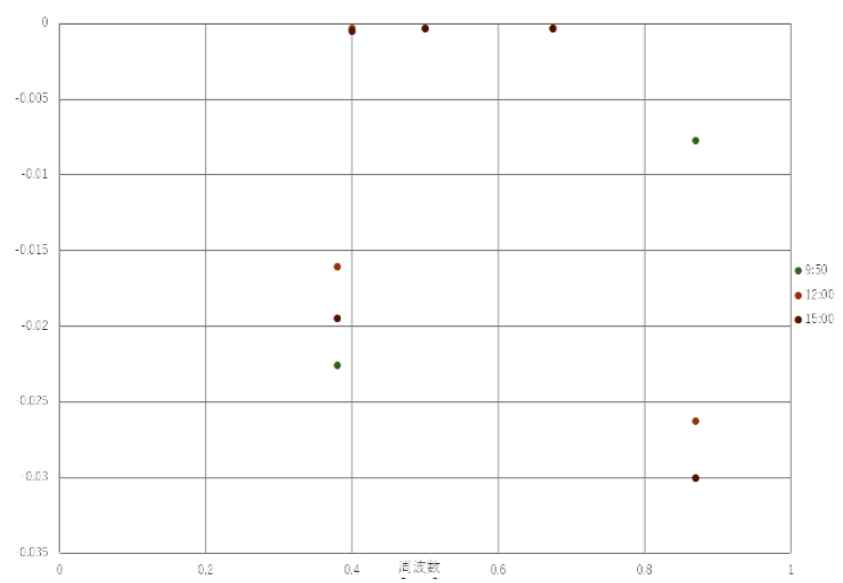

(b)April 13

Fig. 11. Estimated imaginary part of aerosol refractive index

On the other hand, real part of aerosol refractive index which is estimated for 9:00 to 10:20 on April 12 and 9:50 to 15:00 on April 13 is shown in Fig. 12 (a) and (b), respectively.

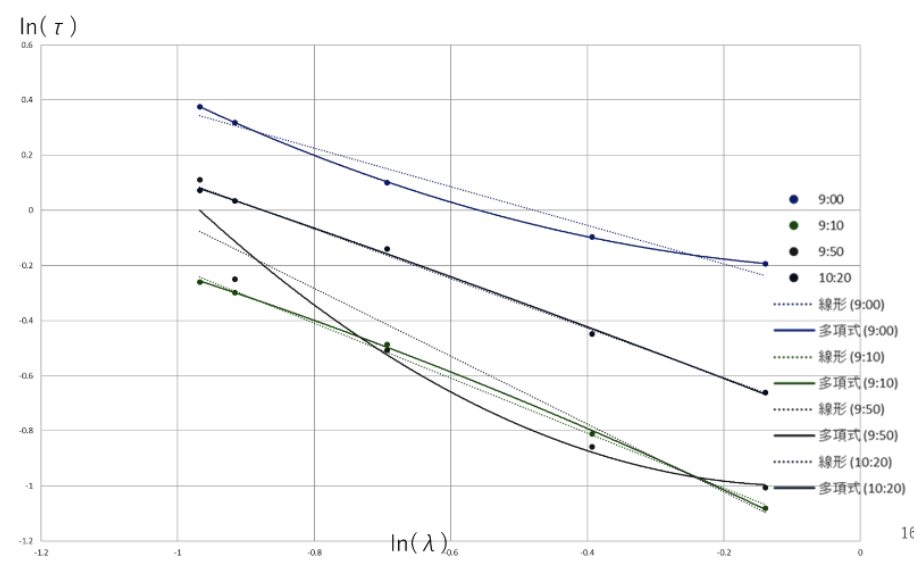

(a)April 12

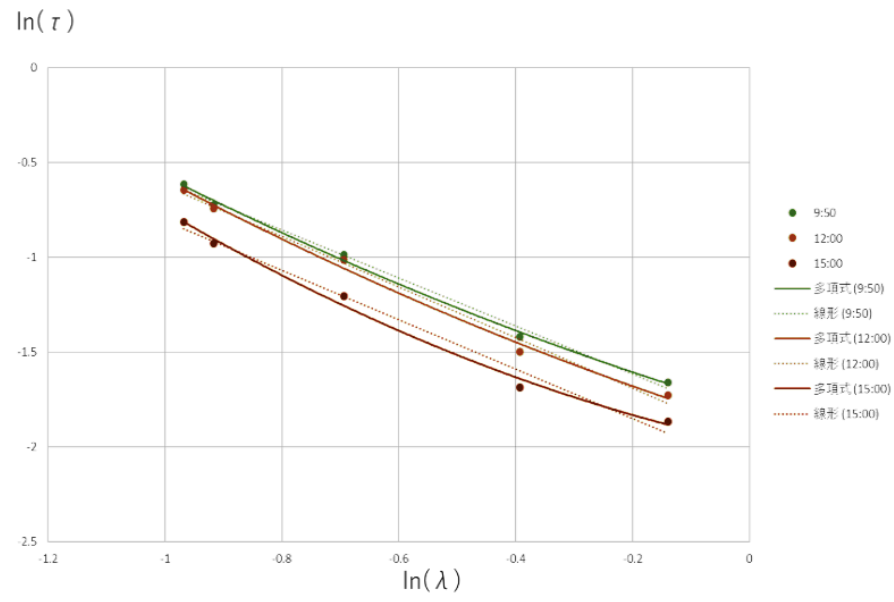

(b)April 13

Fig. 12. Real part of aerosol refractive index which is estimated for April 12 and April 13
Also, relatively large changes are observed for real part of aerosol refractive index during from 9:00 to 10:20 on April 12 while that for 9:50 to 15:00 on April 13 is very stable. Meanwhile, aerosol size distribution which is estimated for 9:00 to 10:20 on April 12 and 9:50 to 15:00 on April 13 is shown in Fig. 13 (a) and (b), respectively. Also, relatively large changes are observed for aerosol size distribution during from 9:00 to 10:20 on April 12 while that for 9:50 to 15:00 on April 13 is very stable. More importantly, aerosol size distribution on April 13 is bi-modal and stable during from 9:50 to 15:00 while that on April 12 is changed dramatically during from 9:10 to 9:50. It is thought type of aerosol particles are changed during the period.

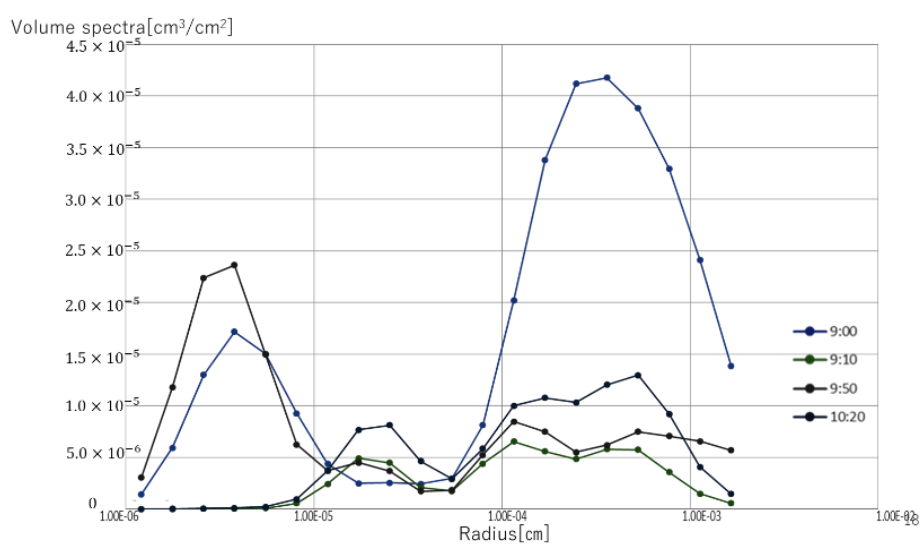

(a)April 12

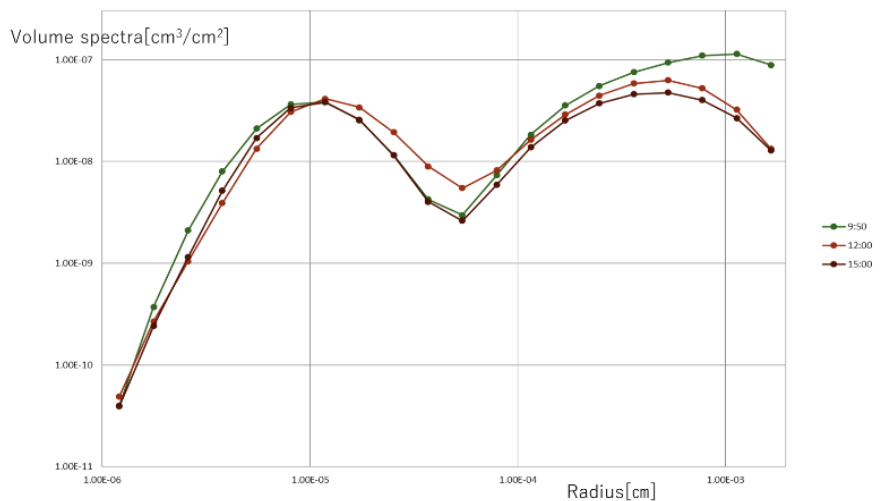

(b)April 13

Fig. 13. Aerosol size distribution which is estimated for April 12 and April 13

\section{E. Another Possible Method for Identification of Relatively Poor Estimation Accuracy of $\mathrm{XCO}_{2}$}

Another possible method for identification of relatively poor estimation accuracy of $\mathrm{XCO}_{2}$ is investigated. The most reliable method is comparison between ground based FTS data derived $\mathrm{XCO}_{2}$ and $\mathrm{XCH}_{4}$ and GOSAT/TANSO-FTS, obviously It does work for the data location at TCCON sites. As mentioned in the previous section, most significant causes for poor accuracy of $\mathrm{XCO}_{2}$ and $\mathrm{XCH}_{4}$ estimations are clouds. Therefore, the method which uses sky-view camera data might be useful. It, however, can be used for the FTS data nearby TCCON sites. Also, TANSO-CAI is applicable to find clouds. It, however, does not work for cirrus cloud detection. 

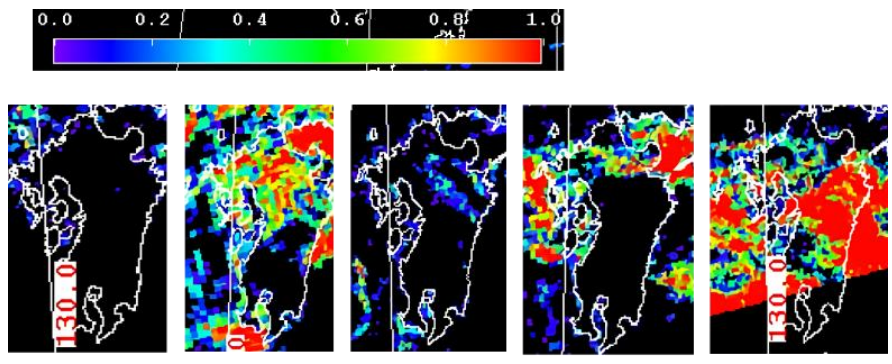

4/4 13:55(JST) 4/12 13:05(JST) 4/13 13:45(JST) 4/19 13:10(JST) 4/24 13:30(JST)

(a) Cloud reflectance
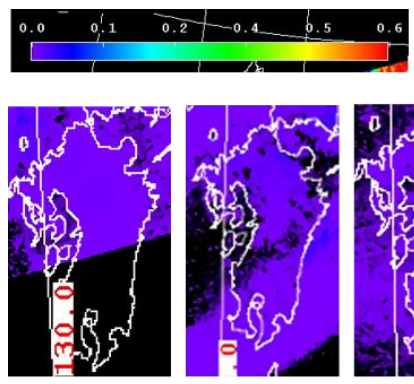

4/4 13:55(JST) 4/12 13:05(JST) 4/13 13:45(JST) 4/19 13:10(JST) 4/24 13:30(JST)

(b) Cirrus cloud reflectance

Fig. 14. MODIS data derived cloud and cirrus cloud reflectance

Therefore, the following method utilizing MODIS data derived cloud reflectance as well as cirrus cloud reflectance is proposed. Fig. 14 (a) shows cloud reflectance on April 4, 12, 13, 19, and 242018 while Fig. 14 (b) shows cirrus cloud reflectance on the same days, respectively. These reflectance are derived from AQUA/MODIS data. Therefore, it measures in the afternoon because local mean time of the AQUA satellite orbit is afternoon. It, however, shows great possibility of cirrus cloud detection.

\section{CONCLUSION}

Quality and cloud flags of GOSAT/TANSO-FTS: Fourier Transform Spectrometer onboard Greenhouse gasses Observation Satellite products taking into account cirrus clouds and thick aerosols are considered and proposed. Influence due to cirrus and thick aerosol on estimation of column $\mathrm{CO}_{2}$ and $\mathrm{CH}_{4}$ with GOSAT/TANSO-FTS data is clarified. Relatively large estimation errors are observed in column $\mathrm{CO}_{2}$ and $\mathrm{CH}_{4}$ retrievals with FTS data in some atmospheric conditions.

In order to find such cases, retrieval results and quality/cloud flags in the GOSAT/TANSO-FTS data products are checked. Through the investigation, it is found that relatively large error is caused by convergence problem due to cirrus clouds and thick aerosols. In the paper, some of the cases of which relatively large estimation error is occurred at the Saga TCCON (The Total Carbon Column Observing Network) site are investigated. Also, a comparative study is conducted between standard products provided by NASA/JPL and the Levenberg-Marquardt based least square method of column $\mathrm{CO}_{2}$ and $\mathrm{CH}_{4}$ retrieval. It is suggested that some improvements of estimation accuracy of column $\mathrm{CO}_{2}$ and $\mathrm{CH}_{4}$ retrieval with GOSAT/TANSO-FTS data can be expected.
The purpose of this research is to develop a method for identifying poor accuracy of $\mathrm{XCO}_{2}$ and $\mathrm{XCH}_{4}$ estimation with GOSAT/TANSO-FTS data. The conventional method is to use the flag which reflect cloud detection with GOSAT/TANSOCAI imagery data and quality of FTS data. It, however, GOSAT/TANSO-CAI does not work for cirrus clouds. Therefore, alternative methods are attempted and proposed here. One of those is to use MODIS data derived cloud reflectance and cirrus cloud reflectance. For the FTS data is acquired around TCCON sites, sky-view camera images are useful. Also, solar irradiance is useful for the FTS data is acquired around meteorological stations which allow measurement data of solar direct irradiance.

There are some reasons for relatively large discrepancy between GGG and the proposed $\mathrm{XCO}_{2}$ estimation methods as well as between ground based measurement data and GOSAT based $\mathrm{XCO}_{2}$ measurement data. Therefore, it is possible to create quality flag through comparisons of the estimated $\mathrm{XCO}_{2}$ and $\mathrm{XCH}_{4}$ derived from the different methods, GGG and Levenberg-Marquardt.

Cirrus cloud (cloud type, MODIS derived cloud reflectance including cirrus cloud reflectance) while, thick aerosol (Refractive index, size distribution, single scattering albedo, optical depth, Angstrom exponent, etc.). Therefore, there is a possibility to identify a poor accuracy of $\mathrm{XCO}_{2}$ and $\mathrm{XCH}_{4}$ estimation by using MODIS data derived cloud reflectance as well as cirrus cloud reflection. Cloud flag can be created with MODIS derived cloud and cirrus cloud reflectance as well as sky-radiometer data derived refractive index and size distribution together with sky view camera data

Further study is required for establishment of $\mathrm{XCO}_{2}$ and $\mathrm{XCH}_{4}$ retrieval method with a variety of remote sensing satellite imagery data.

\section{ACKNOWLEDGMENT}

The author would like to tank Dr. Kurtis Thome of NASA/GSFC and Dr. Satoshi Tsuchida of Advanced Institute of Science and Technology for their valuable comments and suggestions as well as Dr. Liang Xing Ming of NOAA/NESDIS for their discussions.

\section{REFERENCES}

[1] Osamu Uchino, Tetsu Sakai, Tomohiro Nagai, Masahisa Nakasato, Isamu Morino, Tatsuya Yokota, Tsuneo Matsunaga, Nobuo Sugimoto, Kohei Arai, Hiroshi Okumura, Development of transportable Lidar for validation of GOSAT satellite data products, Journal of Remote Sensing Society of Japan, 31, 4, 435-443, 2011

[2] O.Uchino, I.Morino, Y.Yoshida, N.Kikuchi, M.Inoue, K.Nakano, T.Yokota, D.Wunch, P.Wennberg, G.Toon, J.Notholt, V.Sherlock, B.Liley, D.Grifith, S.Kawakami, H.Ohyama, T.Nagai, T.Sakai, Kohei Arai, H.Okumura, Advanced validation of the GOSAT observed CO2 and $\mathrm{CH} 4$ at TCCON and prioritized observation sites, Geophysical Research Abstract, Vol. 14, EGU 2012, General Assembly, 2012.

[3] H.Ohyam, S.Kawakami, Tetsu Tanaka, Isamu Morino, O.Uchino, Makoto Inoue, TSakai, T.Nagai, A.Yamazaki, A.Uchiyama, T.Fukamachi, M.Sakashita, T.Kawasaki, T.Akaho, Kohei Arai, H.Okumura, Observations of XCO2 and $\mathrm{XCH} 4$ with ground-based highresolution FTS at Saga, Japan and comparisons with GOSAT products, Journal of Atmospheric Measurement Technics Discussion, 8, 8, 82578294,2015

[4] Kohei Arai, Masanori Sakashita, Evaluation of Cirrus Cloud Detection Accuracy of GOSAT/CAI and Landsat- 8 with laser Radar: Lidar and 
Confirmation with Calipso Data, International Journal of Advanced Research on Artificial Intelligence, 5, 1, 14-21, 2016.

[5] Kohei Arai, Masanori Sakashita, Hiroshi okumura, Shuichi Kawakami, Kei Shiomi, Hirofumi Ohyama, Comparative Study on Cloud Parameter Estimation AmongGOSAT/CAI, MODIS, CALIPSO/CALIOP and Landsat-8/OLI with Laser Radar as Truth Data, International Journal of Advanced Research on Artificial Intelligence, 5, 5, 21-29, 2016.

[6] I.Morino, O.Uchino, Y.Yoshida, N.Kikuchi, M.Inoue, K.Nakamae, T.Yokota, V.Sherlock, B.Liley, S.Kawakami, H.Ohyama, T.Nagai, T.Sakai, Kohei Arai, H.Okumura, Advanced validation of the GOSAT observed $\mathrm{CO} 2$ and $\mathrm{CH} 4$ at priotized observation sites, AGU Fall Meeting, A063, 2012.

[7] H. Okumura, S.Takubo, T.Kawsaki, I.N.Abdulah, T.Sakai, T.Maki, Kohei Arai, Web based data acquisition and management system for GOSAT validation Lidar data analysis, Proceedings of the SPIE Vol.8537, Conference 8537: Image and Signal Processing for remote Sensing, Paper \#8537-43, system, 2012.

[8] T.Sakai, H. Okumura, T.Kawsaki, I.N.Abdulah, O.Uchino, I.Morino, T.Yokota, T.Nagai, T.Sakai, T.Maki, Kohei Arai, Observation of aerosol parameters at Saga using GOSAT product validation Lidar, Proceedings of the SPIE Vol.8526, Conference 8526: Lidar Remote Sensing for Environmental Monitoring XIII, SPIE Asia-Pacific Remote Sensing, Paper \#8295A-50,IP1, 2012.

[9] Hiroshi Okumura, Shoichiro Takubo, Takeru Kawasaki, Indra Nugraha Abdulah, Osamu Uchino, Isamu Morino, Tatsuya Yokota, Tomohiro Nagai, Tetu Sakai, Takashi Maki, Kohei Arai, Improvement of webbased data acquisition and management system for GOSAT validation Lidar data analysis(2013), SPIE Electronic Imaging Conference, 2013.

[10] Hiroshi Okumura, Kohei Arai, Observation of aerosol properties at Saga using GOSAT product validation LiDAR, Proceedings of the Conference on Image and Signal Processing fo Remote Sensing, SPIE \#ERS13-RS107-38, 2013

[11] T. Sakai, O. Uchino, I. Morino, T. Nagai, S. Kawakami, H. Ohyama, A Uchiyama, A. Yamazaki, Kohei Arai, H. Okumura, Y. Takubo, T. Kawasaki, T. Akaho, T. Shibata, T. Nagahama, Y. Yoshida, N. Kikuchi, B. Liley, V. Sharlock, J. Robinson, T. Yokota, Impact of aerosol and cirrus clouds on the GOSAT observed $\mathrm{CO} 2$ and $\mathrm{CH} 4$ inferred from ground based lidar, sky-radiometer and FTS data at prioritized observation sites,(2013), Proceedings of the 9th International Workshop on Greenhouse Gas measurements from Space, IWGGMS-9, 2013

[12] Osamu Uchino, T.Sakai, T.nagai, I.Morino, H.Ohyama, S.Kawakami, K.Shiomi, T Kawasaki, T.Akaho, H.Okumura, Kohei Arai, T.matsunaga, T.Yokota, Comparison of lower tropospheric ozone column observed by DIAL and GOSAT TANSO-FTS TIR, Proceedings of the AGU Fall Meeting 2013.(2013)

[13] I Morino, T Sakai, T.Nagai, A.Uchiyama, A.Yamazaki, S Kawakami, H.Ohyama, Kohei Arai, H.Okumura, T.Shibata, T.Nagahama, N.Kikuchi, Y.Yoshida, Ben Liley, Vannessa Sherlock, John Robinson, O. Uchino, T.Yokota, Impact of aerosols and cirrus on the GOSAT onboard $\mathrm{CO} 2$ and $\mathrm{CH} 4$ inferred from ground based Lidar, skyradiometer and FTS data at prioritized observation sites, Proceedings of the AGU Fall Meeting 2013.(2013)

[14] O.Uchino, I.Morino, M.Inoue, Y.Yoshida, N.Kikuchi, K.Nakane, T.Yokota, Debra Winch, Coleen M. Roahl,Paul U.Wannberg, Geoffrey C.Toon, Nicholas M.Deuscher, Thorsten Weneke, Justus Notholt, David W., T.Griffich, Vennesa Sherlock, John Robinson, Brian Connor, Ralf Sussmann, Markus Rettinger, Petteri Ahonen, Paul Heikkinen, Esko Kiro, Joseph mendonka, Kinbbely Strong, Frank Hase, Susanne Dohe, Skanakami, H.Ohyama, T.Nagahana, T. Machida, Y.Suwa, H.Matsueda, K.Tsuboi, Colun Sunney, Pieter Tans, Arlyn Anderews, Sebastian C.Biraud, Steven C.Wofsy, T.Sakai, T.Nagai, A.Yamazaki, A.Uchiyama, T.Akaho, T.Kawsaki, H.Okumura, Kohei Arai, ban liley, T.Shibata, On the validation results of five year GOSAT SWIR XCO2 and XCH4 data, Proc. of the IWGGMS-10, 2014.

[15] Osamu Uchino, Isamu Morino, Tetsu Sakai, Toshiharu Izumi, Tomohiro Nagai, Takashi Shibata, Hiroshi Okumura, Kohei Arai, Ben Liley, Gerty Bagtasa, Lidar observations at priotized sites for GOSAT validation, Proceedings of the AGU Fall Meeting 2016.

[16] Osamu Uchino, Isamu Morino, Tetsu Sakai, Toshiharu Izumi, Tomohiro Nagai, Takashi Shibata, Hiroshi Okumura, Kohei Arai, Ben Liloy, Dave Pollard, Gerry Bagtasa, Lider observation at TCCON site to investigate the influence of particles for GOSAT data, Proceedings of the IWGGMS 13, at Helshinki, Finland, 2017.

[17] Kohei Arai, Takashi Higuchi, Hiroshi Okumura, Hirofumi Ohyama, Shuji Kawakami, Kei Shiomi, Influence due to cirrus and thick aerosol on estimation of column $\mathrm{CO} 2$ and $\mathrm{CH} 4$ with GOSAT/FTS data, Proceedings of the COSPAR 2018, A1.1 Space-based and sub-orbital observations of atmospheric physics and chemistry, $2018 .$.

\section{AUTHORS PROFILE}

Kohei Arai, He received BS, MS and PhD degrees in 1972, 1974 and 1982, respectively. He was with The Institute for Industrial Science and Technology of the University of Tokyo from April 1974 to December 1978 also was with National Space Development Agency of Japan from January, 1979 to March, 1990. During from 1985 to 1987, he was with Canada Centre for Remote Sensing as a Post Doctoral Fellow of National Science and Engineering Research Council of Canada. He moved to Saga University as a Professor in Department of Information Science on April 1990. He was a councilor for the Aeronautics and Space related to the Technology Committee of the Ministry of Science and Technology during from 1998 to 2000. He was a councilor of Saga University for 2002 and 2003. He also was an executive councilor for the Remote Sensing Society of Japan for 2003 to 2005. He is an Adjunct Professor of University of Arizona, USA since 1998. He also is Vice Chairman of the Science Commission "A" of ICSU/COSPAR since 2008 then he is now award committee member of ICSU/COSPAR. He wrote 37 books and published 570 journal papers. He received 30 of awards including ICSU/COSPAR Vikram Sarabhai Medal in 2016, and Science award of Ministry of Mister of Education of Japan in 2015. He is now Editor-in-Chief of IJACSA and IJISA. http://teagis.ip.is.saga-u.ac.jp/index.ht 